\title{
Impact of Cytotoxin-Associated Gene Product-A Positive Helicobacter Pylori Strains on Micro-albuminuria in Type 2 Diabetes
}

\author{
Amany Ibrahim ${ }^{1}$, Tarik Zaher ${ }^{2}$,Tarek A. Ghonemy ${ }^{*}$, Shymaa Abd El-Azim³, Marwa Abd El-Azim³ \\ Departments of (1) Internal Medicine, (2) Tropical Medicine, and (3) Microbiology and Immunology, Faculty of Medicine, Zagazig \\ University, Egypt.
}

\begin{abstract}
Introduction: Available data on the possible association between Helicobacter pylori (H. pylori) infection and diabetes mellitus (DM) are contradictory. The prevalence of cytotoxin associated gene product A (cagA) positive H. pylori is high in Egypt. This study aims to examine its association with type $2 \mathrm{DM}$, and its effect on glycemic control and the occurrence of microalbuminuria.
\end{abstract}

Methods: The study involved 98 dyspeptic type 2 diabetic patients and 102 dyspeptic non-diabetic subjects who underwent upper gastrointestinal tract endoscopy in Zagazig university hospital. H. pylori infection was diagnosed by histopathology and/or culture. The presence of cagA positive strains was confirmed by polymerase chain reaction (PCR) and gel electrophoresis. Fasting blood sugar (FBS), glycosylated hemoglobin (HbA1c) and urinary albumin excretion ratio (UAER) were compared between infected and non-infected diabetic patients.

Results: Diabetic patients had similar age and gender distribution but significantly higher body mass index (BMI) compared to controls. The prevalence of $H$. pylori infection $(54.1 \%$ versus $56.9 \%, \mathrm{P}=0.3)$ and the prevalence of cagA positive $H$. pylori strains (40.8\% versus $36.3 \%$, $\mathrm{P}=0.1$ ) were not significantly different between the two groups. Diabetic patients infected with cagA positive H. pylori strains had higher mean FBS $(199 \pm 22$ versus $163 \pm 20, \mathrm{P}=0.00)$, higher mean HbA1c $(8.6 \pm 0.8$ versus $6.3 \pm 0.8, \mathrm{P}=0.00)$ and higher rate of microalbuminuria $(67.5 \%$ versus $10.3 \%, \mathrm{P}=0.00)$ than non infected diabetic patients.

Conclusion: $H$. pylori infection with cagA positive strains was similarly common in dyspeptic diabetic patients and controls. It was associated with poorer

* Corresponding author; Zagazig University, Egypt.

E mail: tarekghonemy@hotmail.com glycemic control and higher rates of microalbuminuria in diabetic subjects.

Key words: cagA positive strains; Diabetes mellitus; Helicobatcer pylori; Microalbuminuria

\section{The authors declared no conflict of interest}

\section{Introduction}

Helicobacter pylori is a gram-negative microaerophilic spiral bacterium that inhabits the mucous layer covering gastric epithelial cells. It is a major cause of chronic superficial gastritis, duodenal or gastric ulceration, and gastric adenocarcinoma. Many strains of $H$. pylori produce an immunogenic high molecular weight protein called cytotoxin associated gene product A (cagA). Infection with such strains can be detected by a simple serological test for anti-cagA antibodies. The ability to induce cytokines differs among $H$. pylori strains; cagA positive strains induce various kinds of cytokines and may cause severe inflammation, whereas cagA negative strains induce IL-8 and IL-1 beta only weakly and may cause only mild inflammation [1]. H. pylori strains which express cagA are more often associated with peptic ulceration and gastric adenocarcinoma than are cagA negative strains [2].

Infection by cagA positive $H$. pylori strains was recently reported to have an association with increased intima/ media thickness and poorer short-term outcome in atherosclerotic stroke patients [3]. H. pylori eradication therapy was also reported to improve the platelet count in $H$. pylori positive patients with idiopathic thrombocytopenic purpura (ITP) [4]. These associations may be due to cytokine induction by $H$. pylori or to antigen mimicry between it and host antigens.

In patients with diabetes mellitus (DM), chronic infections are frequent and severe, due to the impairment of their immune status. However, data on the prevalence of $H$. pylori infection in diabetics are scanty and contradictory. 
Community based surveys gave conflicting results about the prevalence of gastro-intestinal (GI) tract symptoms in persons with or without DM $[5,6]$. Some studies reported no difference in $H$. pylori infection rates between diabetic patients and controls [7-11], while other studies reported a higher rate of $H$. pylori infection in diabetic patients [12-15].

The prevalence of cagA positive $H$. pylori is common in Egypt and is related to the clinical presentation, being lowest in asymptomatic controls (11.1\%) and increasingly prevalent in non-ulcer dyspepsia (40\%), peptic ulcer (66.7\%), and gastric cancer (89\%) [16].

This study was performed to examine the possible relationship between infections by cagA positive $H$. pylori strains, occurrence of microalbuminuria and reduced glycemic control in type 2 diabetic patients.

\section{Methods}

This is a case-control study conducted in Zagazig University Hospital. It involved 102 consecutive dyspeptic non-diabetic subjects (58 males, 44 females, mean age $46 \pm 6.2$ years) as controls and 98 dyspeptic type 2 diabetic patients (53 males, 45 females, mean age $45 \pm 5.4$ years) as cases. All subjects gave informed consent before participation. Dyspeptic symptoms were defined by the presence of epigastric pain, bloating, nausea, vomiting and early satiety. Subjects were excluded if they had ischemic chest pain, previous stroke, decompensated heart failure, connective tissue disorders, neoplastic diseases, hematological diseases, renal impairment, history of gastric surgery, cholecystectomy or peptic ulcer, or previous $H$. pylori eradication. We also excluded patients who were on non steroidal anti-inflammatory drugs, antibiotics, $\mathrm{H} 2$ blocker, or proton pump inhibitors within two months prior to the procedure. Investigations included fasting blood glucose, glycosylated hemoglobin (HbA1c), and 24 hours urinary albumin excretion rate (UAER). UAER was measured using a solid-phase enzyme-linked immunosorbent assay (ELISA) (Micro Albumin Quantitative test; DRG International, Inc., USA) with a lowest detection limit of $1 \mathrm{mcg} / \mathrm{ml}$. Microalbuminuria was defined by an UAER of $30-299 \mathrm{mg} / 24$ hours.

All subjects underwent endoscopy after overnight fasting using fiber-optic endoscope (ZIF XQ230; Olympus, Center Valley, PA) and two biopsies were taken from each subject for bacterial isolation; the first biopsy was taken about $2 \mathrm{~cm}$ proximal to the pylorus and the second biopsy was taken from the corpus of the stomach. The specimens were transported to the laboratory in $0.2 \mathrm{ml}$ of $20 \%$ glucose broth (BioMerieux) in sterile screw-capped tubes at $4^{\circ} \mathrm{C}$ within 2 hours. Before culture, the specimens were grounded and homogenized with a sterile mortar and pestle in $1 \mathrm{ml}$ of saline. The biopsy homogenate was placed onto a Columbia blood agar plate supplemented with trimethoprim, vancomycin, and amphotericin $\mathrm{B}$. The plates were incubated under microaerophilic conditions; $5 \% \mathrm{O} 2,7.5 \% \mathrm{CO} 2,7.5 \% \mathrm{H} 2$, and $80 \% \mathrm{~N} 2$ using CampyPak microaerophilic system envelopes (Columbia Diagnostics, Springfield, VA) at $37^{\circ} \mathrm{C}$ for up to 10 days. Plates were checked every other day for growth. On day 5 , plates without obvious growth were subcultured onto Columbia blood agar plates to promote growth of lightly growing colonies that may have been missed visually. All colonies with macroscopic appearance suggesting H. pylori (small, circular and smooth) were tested by Gram-stain, oxidase, catalase, and urease tests to confirm identification [17].

The H. pylori infection was considered positive if culture and/or histopathological examination and rapid urease test were positive. All the isolated $H$. pylori were suspended in $2 \mathrm{ml}$ of tryptone soy broth medium containing $20 \%$ (vol/vol) glycerol and kept frozen at $-70^{\circ} \mathrm{C}$ until DNA extraction was performed [18]. To remove culture from frozen stock, vial was placed in an alcohol-dry ice bath. A small amount of frozen culture was scraped into tip of a Pasteur pipette. Columbia blood agar plate was inoculated. $5 \mathrm{ml}$ Brucella broth was inoculated with $H$. pylori isolates and put in $\mathrm{CO} 2$ incubator under microaerophilic condition for 2-3 days. $1.5 \mathrm{ml}$ of the culture was spun in a microcentrifuge for 2 minutes at $13.000 \mathrm{rpm}$ to obtain a compact pellet. The supernatant was discarded. The DNA was extracted from the pellets by use of the QIAamp DNA kit (QIAGEN, Hilden, Germany) according to the manufacturer's recommendations and DNA stored at $-20^{\circ} \mathrm{C}$ until analysis. DNA extraction negative controls were performed in parallel by including sterile tubes without samples to check for contamination of the DNA extraction reagents. Polymerase Chain Reaction (PCR) was performed for detection of cagA gene. It was done by using a primer pair: (forward: 5' AAT ACA CCAACG CCT CCA AG 3', reverse: 5'TTG TTG CCG CTT TTG CTC TC 3'). PCR was carried out in a $25 \mu \mathrm{L}$ volume in thermal cycler (Perkin Elmer-Cetus, USA). Cycling conditions were as followed: initial denaturation at $95^{\circ} \mathrm{C}$ for 5 minutes, followed by 34 cycles of denaturation at $94^{\circ} \mathrm{C}$ for 1 minute, annealing at $53^{\circ} \mathrm{C}$ for 1 minute, and extension at $94^{\circ} \mathrm{C}$ for 1 minute. A final extension cycle was extended to 5 minutes at $72^{\circ} \mathrm{C}$. A 400 -base pair amplification product was detected on $2 \%$ agarose gel. Ten $\mu$ volumes of each PCR mixture were mixed with the two $\mu 1$ gel loading buffer and subjected to gel electrophoresis ( $2 \%$ agarose).

Statistical analysis was performed using SPSS version 13. Proportions were compared using Chi square test 
Table 1: Demographic and clinical characteristics of dyspeptic subjects with and without type II diabetes mellitus

\begin{tabular}{llll}
\hline Clinical and laboratory data & $\begin{array}{l}\text { Diabetic } \\
\text { dyspeptic subjects }(\mathbf{n = 9 8})\end{array}$ & $\begin{array}{l}\text { Non-diabetic } \\
\text { dyspeptic subjects ( }\end{array}$ & P value \\
\hline Age (years), mean \pm SD & $45.6 \pm 5.8$ & $44.9 \pm 6.3$ & 0.367 \\
Male gender, number (\%) & $53(54.1 \%)$ & $58(56.9 \%)$ & 0.692 \\
BMI (kg/m $)$, mean \pm SD & $25.8 \pm 3.5$ & $21.5 \pm 1.8$ & 0.000 \\
H. pylori infection, number (\%) & $53(54.1 \%)$ & $58(56.9 \%)$ & 0.321 \\
Infection with cagA positive strains, number (\%) & $40(40.8 \%)$ & $37(36.3 \%)$ & 0.145 \\
Microalbuminuria, number (\%) & $30(30.6 \%)$ & $22(21.6 \%)$ & 0.145 \\
\hline
\end{tabular}

Table 2: Indices of glycemic control and prevalence of microalbuminuria among cagA positive and cagA negative diabetic patients

\begin{tabular}{llll}
\hline Clinical and laboratory data & $\begin{array}{l}\text { cagA positive } \\
\text { diabetic patients }(\mathbf{n}=\mathbf{4 0})\end{array}$ & $\begin{array}{l}\text { cagA negative } \\
\text { diabetic patients }(\mathbf{n}=\mathbf{5 8})\end{array}$ & P value \\
\hline Fasting blood glucose (mg/dl), mean \pm SD & $199 \pm 22$ & $163 \pm 20$ & 0.000 \\
HBA1c (\%), mean \pm SD & $8.6 \pm 0.8$ & $6.3 \pm 0.8$ & 0.000 \\
Microalbuminuria, number (\%) & $27(67.5 \%)$ & $6(10.3 \%)$ & 0.000 \\
\hline
\end{tabular}

while means were compared using student-t test. P value $<0.05$ was considered significant.

\section{Results}

Diabetic patients and non-diabetic subjects had similar age and gender distribution, but diabetic subjects had significantly higher body mass index (BMI). The prevalence of $H$. pylori infection was not different between the two groups $(54.1 \%$ versus $56.9 \%, \mathrm{P}=0.3)$. The prevalence of cagA positive $H$. pylori infection was not different between diabetic and non-diabetic subjects (40.8\% versus $36.3 \%, \mathrm{P}=0.1)$ (Table 1$)$.

Indices of glycemic control were significantly different between diabetic patients infected with cagA positive $H$. pylori strains and diabetic patients who tested negative for these strains, with the former group having poorer glycemic control. Diabetic patients who were infected by cagA positive $H$. pylori strains also had significantly higher rates of microalbuminuria (Table 2).

\section{Discussion}

There is little and contradictory data about the relationship between $H$. pylori infection and diabetes mellitus. Diabetics have impaired cellular and humoral immunity that encourage chronic infections, and they often have reduced gastrointestinal motility and autonomic neuropathy which may enhance bacterial colonization and overgrowth. On the other hand, diabetic patients often have reduced acid secretion or achlorohydria, and may have microangiopathy of gastric mucosa. All these factors decrease the chance of growth of $H$. pylori.

In this series, we found no difference in the prevalence of H. pylori infection or in the prevalence of cagA positive strains between dyspeptic diabetic and non-diabetic subjects. This is in agreement with previous studies reported by Candelli et al [10], Anastasios et al [7], Demir et al [8] Xia et al [9], and Ko et al [11]. However, other studies reported a higher prevalence of $H$. pylori infection in type 2 diabetic patients in comparison to non diabetic subjects [12-15]. This discrepancy between results may be attributable to differences in sensitivity of methods used to detect infection or to differences in selection of control groups and sample sizes.

The prevalence of microalbuminuria was $30.6 \%$ in this group of diabetic subjects compared to $21.6 \%$ in nondiabetic subjects, but the difference was not statistically significant, probably due to the small sample size. However, diabetic subjects infected with cagA positive strains had a markedly higher rate of microalbuminuria compared to cagA negative patients $(67.5 \%$ versus $10.3 \%, \mathrm{P}=0.00)$. This association may be related to potential cross mimicry between anti-cagA antigens and renal antigens, an area that warrants further research. 
We found evidence of significantly better glycemic control among diabetic subjects without cagA $H$. pylori infection compared to infected diabetics. This effect of H. pylori infection was not detected by Demir et al [8], but was reported by Fernandini-Paredes et al [19].

Aydemir et al used HOMA-IR (homeostasis model assessment of insulin resistance) level to assess insulin resistance in $36 \mathrm{H}$. pylori positive and $27 \mathrm{H}$. pylori negative subjects [20]. They found an HOMA-IR level of $2.56 \pm 1.54$ in the $H$. pylori positive group compared to $1.73 \pm 1.1$ in the $H$. pylori negative group $(\mathrm{P}<0.05)$. These data provided evidence for an association between chronic $H$. pylori infection and insulin resistance. H. pylori may induce chronic hyperinsulinemia by decreasing the serum concentration of somatostatin [21] which has an inhibiting effect on insulin release. The induction of cytokines by cagA positive strains may also stimulate the secretion of insulin counter-regulatory hormones. $H$. pylori infection was reported to be associated with lower fasting plasma glucose concentrations among women [22], and the findings of Bégué et al suggest that eradication of $H$. pylori infection in patients with type 1 diabetes might be associated with better glycemic control [23].

Microalbuminuria is an early marker of diabetic nephropathy in type $2 \mathrm{DM}$. We report a significantly and markedly higher rate of microalbuminuria among cagA positive diabetic patients compared to cagA negative patients. This association may be related to the enhanced production of cytokines in cagA positive strain infected patients. Antigen mimicry between cagA positive strains and endothelial cells [24] may trigger immune-mediated injury at the level of the glomerulus resulting in albumin leakage.

This association warrants further investigations. The potential therapeutic advantage of $H$. pylori eradication in the management of DM and its complications remains to be determined.

\section{Conclusion}

H. pylori infection with cagA positive strains was common among this group of dyspeptic diabetic patients with no significant difference from controls. Infection with cagA positive strains was associated with poorer glycemic control and higher rates of microalbuminuria.

\section{References}

1. Yamaoka Y, Kita M, Kodama T, Sawai N, Kashima $\mathrm{K}$, Imanishi J. Induction of various cytokines and development of severe mucosal inflammation by cagA gene positive Helicobacter pylori strains. Gut. 1997 Oct;41(4):442-51.

2. Blaser MJ, Perez-Perez GI, Kleanthous H, Cover TL, Peek RM, Chyou PH, Stemmermann GN, Nomura A. Infection with Helicobacter pylori strains possessing cagA is associated with an increased risk of developing adenocarcinoma of the stomach. Cancer Res. 1995 May;55(10):2111-5.

3. Diomedi M, Pietroiusti A, Silvestrini M, Rizzato B, Cupini LM, Ferrante F, Magrini A, Bergamaschi A, Galante A, Bernardi G. cagA-positive Helicobacter pylori strains may influence the natural history of atherosclerotic stroke. Neurology. 2004 Sep;63(5):800-4.

4. Kodama M, Kitadai Y, Ito M, Kai H, Masuda H, Tanaka S, Yoshihara M, Fujimura K, Chayama K. Immune response to cagA protein is associated with improved platelet count after Helicobacter pylori eradication in patients with idiopathic thrombocytopenic purpura. Helicobacter. 2007 Feb;12(1):36-42.

5. Maleki D, Locke GR 3rd, Camilleri M, Zinsmeister AR, Yawn BP, Leibson C, Melton LJ 3rd. Gastrointestinal tract symptoms among persons with diabetes mellitus in the community. Arch Intern Med. 2000 Oct;160(18): 2808-16.

6. Bytzer, Talley NT, Leemon, Young LJ, Jones MP, Horowitz M. Prevelance of gastrointestinal symptoms associated with diabetes mellitus: a populationbased survey of 15,000 adults. Arch Intern Med. 2001 Sep;161(16):1989-96.

7. Anastasios R, Goritsas C, Papamihail C, Trigidou R, Garzonis P, Ferti A. Helicobacter pylori infection in diabetic patients: prevalence and endoscopic findings. Eur J Intern Med. 2002 Sep;13(6):376.

8. Demir M, Gokturk HS, Ozturk NA, Kulaksizoglu M, Serin E, Yilmaz U. Helicobacter pylori prevalence in diabetes mellitus patients with dyspeptic symptoms and its relationship to glycemic control and late complications. Dig Dis Sci. 2008 Oct;53(10):2646-9.

9. Xia HH, Tally NJ, Kam EP. Young LJ, Hammer J, Horowitz M. Helicobacter pylori infection is not associated with diabetes mellitus nor with upper gastrointestinal symptoms in diabetes mellitus. Am J Gastroenterol. 2001 Apr;96(4):1039-46.

10. Candelli M, Rigante D, Marietti G, Nista EC, Crea F, Bartolozzi F, Schiavino A, Pignataro G, Silveri NG, Gasbarrini G, Gasbarrini A. Helicobacter pylori, gastrointestinal symptoms and metabolic control in young type 1 diabetes mellitus patients. Pediatrics. 2003 Apr;111(4 Pt 1):800-3. 
11. Ko GT, Chan FK, Chan WB, Sung JJ, Tsoi CL, To KF, Lai CW, Cockram CS. Helicobacter pylori infection in Chinese subjects with type 2 diabetes. Endocr Res. 2001 Feb-May;27(1-2):171-7.

12. Maule S, Lombardo L, Rossi C, Crocellà L, Masoero G, Della Monica P, Catalfamo E, Calvo C, Mecca F, Quadri R. Helicobacter pylori infection and gastric function in primary autonomic neuropathy. Clin Auton Res. 2002 Jun;12(3):193-6.

13. Hamed SA, Amine NF, Galal GM, Helal SR, Tag El-Din LM, Shawky OA, Ahmed EA, Abdel Rahman MS. Vascualr risk and complication in diabetes mellitus: the role of Helicobacter pylori infection. J Stroke Cerebrovasc Dis. 2008 Mar-Apr;17(2):86-94.

14. Bener A, Micallef R, Afifi M, Derbala M, Al-Mulla HM, Usmani MA. Association between type 2 diabetes mellitus and Helicobacter pylori infection. Turk J Gastroenterol. 2007 Dec;18(4):225-9.

15. Gulcelik NE, Kaya E, Demirbas B, Culha C, Koc G, Ozkaya M, Cakal E, Serter R, Aral Y. Helicobacter pylori prevalence in diabetic patients and its relationship with dyspepsia and autonomic neuropathy. J Endocrinol Invest. 2005 Mar;28(3):214-7.

16. Said Essa A, Alaa Eldeen Nouh M, Mohammed Ghaniam N, Graham DY, Said Sabry H. Prevalence of cagA in relation to clinical presentation of Helicobacter pylori infection in Egypt. Scand J Infect Dis. 2008;40(9):730-3.

17. Mégraud F. How should Helicobacter pylori infection be diagnosed? Gastroenterology. 1997 Dec;113(6 Suppl):S93-8.
18. Isenberg HD. Characterization of pathogenic microorganisms by genomic fingerprinting with arbitrarily primed PCR. In: Isenberg HD, editor. Essential Procedures doe Clinical microbiology. Washington (DC): ISM press;1998. p. 658-60.

19. Fernandini-Paredes GG, Mezones-Holguin E, VargasGonzales R, Pozo-Briceño E, Rodriguez-Morales AJ. In patients with type 2 diabetes mellitus, are glycosylated hemoglobin levels higher for those with Helicobacter pylori infection than those without infection? Clin Infect Dis. 2008 Jul;47(1):144-6.

20. Aydemir S, Bayraktaroglu T, Sert M, Sokmen C, Atmaca H, Mungan G, Gun BD, Borazan A, Ustundag Y. The effect of Helicobacter pylori on insulin resistance. Dig Dis Sci. 2005 Nov;50(11):2090-3.

21. Kaneko H, Konagaya T, Kusugami K. Helicobacter pylori and gut hormones. J Gastroenterol. 2002;37(2):7786.

22. Peach HG, Barnett NE. Helicobacter pylori infection and fasting plasma glucose concentration. J Clin Pathol. 2001 Jun;54(6):466-9.

23. Bégué RE, Gómez R, Compton T, Vargas A. Effect of Helicobacter pylori Eradication in the Glycemia of children with type 1 diabetes. South Med J. 2002 Aug;95(8):842-5.

24. Franceschi F, Sepulveda AR, Gasbarrini A, Pola P, Silveri NG, Gasbarrini G, Graham DY, Genta RM. Crossreactivity of anti-cagA antibodies with vascular wall antigens: possible pathogenic link between Helicobacter pylori infection and atherosclerosis. Circulation. 2002 Jul;106(4):430-4. 